OPEN ACCESS

Edited by:

Jiexi Wang,

Central South University, China

Reviewed by:

Hong Guo,

Yunnan University, China

Xiaobo Ji,

Central South University, China

*Correspondence:

Hongjun Yue

hjyue@fjirsm.ac.cn

${ }^{\dagger}$ These authors have contributed equally to this work.

Specialty section:

This article was submitted to Physical Chemistry and Chemical

Physics,

a section of the journal

Frontiers in Chemistry

Received: 24 January 2018 Accepted: 22 February 2018

Published: 09 March 2018

Citation:

Zhong G, Chen H, Huang X, Yue H and Lu C (2018) High-Power-Density,

High-Energy-Density Fluorinated

Graphene for Primary Lithium

Batteries. Front. Chem. 6:50.

doi: $10.3389 /$ fchem.2018.00050

\section{High-Power-Density, High-Energy-Density Fluorinated Graphene for Primary Lithium Batteries}

\author{
Guiming Zhong ${ }^{1,2 \dagger}$, Huixin Chen ${ }^{1,2 \dagger}$, Xingkang Huang ${ }^{3 \dagger}$, Hongjun Yue $^{1,2 *}$ and \\ Canzhong $L u^{1,2}$
}

${ }^{1}$ CAS Key Laboratory of Design and Assembly of Functional Nanostructures, and Fujian Provincial Key Laboratory of Nanomaterials, Fujian Institute of Research on the Structure of Matter, Chinese Academy of Sciences, Fuzhou, China, ${ }^{2}$ Xiamen Institute of Rare Earth Materials, Haixi Institutes, Chinese Academy of Sciences, Xiamen, China, ${ }^{3}$ Department of Mechanical Engineering, University of Wisconsin-Milwaukee, Milwaukee, WI, United States

$\mathrm{Li} / \mathrm{CF}_{\mathrm{X}}$ is one of the highest-energy-density primary batteries; however, poor rate capability hinders its practical applications in high-power devices. Here we report a preparation of fluorinated graphene $\left(\mathrm{GF}_{\mathrm{x}}\right)$ with superior performance through a direct gas fluorination method. We find that the so-called "semi-ionic" C-F bond content in all C-F bonds presents a more critical impact on rate performance of the $\mathrm{GF}_{\mathrm{X}}$ in comparison with $\mathrm{sp}^{2} \mathrm{C}$ content in the $\mathrm{GF}_{\mathrm{x}}$, morphology, structure, and specific surface area of the materials. The rate capability remains excellent before the semi-ionic $\mathrm{C}-\mathrm{F}$ bond proportion in the $\mathrm{GF}_{\mathrm{X}}$ decreases. Thus, by optimizing semi-ionic $\mathrm{C}-\mathrm{F}$ content in our $\mathrm{GF}_{\mathrm{X}}$, we obtain the optimal $x$ of 0.8 , with which the $\mathrm{GF}_{0.8}$ exhibits a very high energy density of 1,073 Wh $\mathrm{kg}^{-1}$ and an excellent power density of $21,460 \mathrm{~W} \mathrm{~kg}^{-1}$ at a high current density of $10 \mathrm{Ag}^{-1}$. More importantly, our approach opens a new avenue to obtain fluorinated carbon with high energy densities without compromising high power densities.

\footnotetext{
Keywords: fluorinated graphene, carbon fluoride, primary lithium battery, nuclear magnetic resonance, high power density
}

\section{INTRODUCTION}

Fluorinated carbon $\left(\mathrm{CF}_{\mathrm{x}}\right)$ possesses a very high theoretical energy density $\left(2,180 \mathrm{Wh} \mathrm{kg}^{-1}\right.$ when $\mathrm{x}$ equals 1 for fluorinated graphite) as a cathode material for primary lithium batteries, thus has been strongly desired in many civil and military applications that require a long service-life, wide range of operating temperatures, as well as high energy densities and reliability. Fluorinated graphite has been widely investigated (Nakajima et al., 2002; Guérin et al., 2004; Zhang Q. et al., 2010). Besides graphite, other types of carbons such as carbon nanotubes, carbon nanofibers, C60, and mesoporous carbon, have also been applied for fluorination (Matsuo and Nakajima, 1996; Mickelson et al., 1998; Lam and Yazami, 2006; Yazami et al., 2007; Zhang W. et al., 2010; Fulvio et al., 2011; Guérin et al., 2012). Among these, a fluorinated mesoporous carbon $\left(\mathrm{CF}_{0.54}\right)$ and a fluorinated coke displayed excellent performance; the fluorinated mesoporous carbon delivered a capacity of $515 \mathrm{mAh} \mathrm{g}^{-1}$ with discharge plateau of $2.75 \mathrm{~V}$ at a current rate of $5 \mathrm{C}$ (Fulvio et al., 2011), while the fluorinated coke displayed a maximum power density of about $14,400 \mathrm{~W} \mathrm{~kg}^{-1}$ with energy 
density of $500 \mathrm{Wh} \mathrm{kg}^{-1}$ (Lam and Yazami, 2006). However, the power densities of these materials are far from satisfaction because of the poor electronic conductivity of the $\mathrm{CF}_{\mathrm{x}}$ materials due to the strong covalent C-F bond.

Coating of highly conductive materials, such as carbon, polypyrrole, and polyaniline on the surface of carbon fluorides is helpful to improve the rate capability (Zhang Q. et al., 2010; Groult et al., 2011; Li et al., 2016); for example, a graphite fluoride coated with polyaniline delivered an energy density of about $1,200 \mathrm{Wh} \mathrm{kg}^{-1}$ with power density higher than $10,000 \mathrm{~W} \mathrm{~kg}^{-1}$ at current rate of $8 \mathrm{C}$ (Li et al., 2016). An amazing rate performance $\left(48,800 \mathrm{~W} \mathrm{~kg}^{-1}\right.$ at $\left.30 \mathrm{C}\right)$ was achieved by reducing the fluorine content on the surface of the carbon fluorides through hydrothermal method, which greatly improved the electronic conductivity (Dai et al., 2014). However, the hydrothermal reaction would be restricted for practical application because it could introduce a large amount of hydroxyl group, jeopardizing the calendar life of the $\mathrm{Li} / \mathrm{CF}_{\mathrm{x}}$ battery.

Fluorinated graphene, as a two-dimensional (2D) material, can shorten the diffusion path of lithium ions, which is helpful for rapid transfer of lithium ions (Zhang S. S. et al., 2009; Feng et al., 2016), thus opening an alternative avenue to chase excellent rate capability. Until now the best fluorinated graphene reported in the literature only can work at 5C, gaining a capacity of 356 mAh g ${ }^{-1}\left(\mathrm{GF}_{0.47}\right)$ (Damien et al., 2013; Meduri et al., 2013; Zhao et al., 2014; Feng et al., 2016). Therefore, uncovering the reasons hindering fluorinated graphene from achieving excellent rate capability is highly desired.

In this study, a fluorinated multilayered graphene $\left(\mathrm{GF}_{\mathrm{x}}\right)$ was prepared by a direct gas fluorination of RGO instead of graphene oxides (Damien et al., 2013; Meduri et al., 2013; Zhao et al., 2014; Feng et al., 2016), and was investigated using ${ }^{13} \mathrm{C}$ and ${ }^{19}$ F NMR spectra, indicating that the controlled formation of the so-called "semi-ionic" C-F bond in the $\mathrm{GF}_{\mathrm{x}}$ is the most critical factor to achieve high power densities with high energy densities. With an optimal semi-ionic C-F bond ratio, our $\mathrm{GF}_{\mathrm{X}}$ showed extraordinary performance with a power density of $21,460 \mathrm{~W} \mathrm{~kg}^{-1}$ and an energy density of $1,073 \mathrm{Wh} \mathrm{kg}^{-1}$ when the $\mathrm{x}$ in $\mathrm{GF}_{\mathrm{x}}$ equals 0.8 , superior to most of the previously reported fluorinated carbons (Mickelson et al., 1998; Lam and Yazami, 2006; Shulga et al., 2007; Yazami et al., 2007; Zhang W. et al., 2010; Fulvio et al., 2011; Groult et al., 2011; Guérin et al., 2012; Damien et al., 2013; Meduri et al., 2013; Sun et al., 2014; Zhao et al., 2014; Feng et al., 2016; Li et al., 2016; Wang et al., 2016). In addition, our approach applied to synthesize $\mathrm{GF}_{\mathrm{x}}$ is facile, and easy for scale-up, exhibiting very promising practical application.

\section{EXPERIMENTAL}

\section{Preparation of Fluorinated Graphene}

Fluorinated graphenes were prepared by a one-step gas-phase fluorination of RGO as described in previous work (Yue et al., 2013; Shao et al., 2016). Graphene oxides were prepared using Hummers method (Hummers and Offeman, 1958), which was subjected to thermal reduction for $10 \mathrm{~h}$ under a $\mathrm{H}_{2}$ flow (5 vol. \% in $\mathrm{Ar}$ ) of $20 \mathrm{sccm}$ at $1,000^{\circ} \mathrm{C}$. The resulting RGO was employed to prepared fluorinated graphene materials at 400,430 , and $460^{\circ} \mathrm{C}$ in fluorinating gas atmosphere for $12 \mathrm{~h}$, obtaining $\mathrm{GF}_{0.5}, \mathrm{GF}_{0.8}$, and $\mathrm{GF}_{1.1}$, respectively. The $\mathrm{F} / \mathrm{C}$ atomic ratios in these samples were determined by quantitative ${ }^{13} \mathrm{C} N M R$ : $\mathrm{F} / \mathrm{C}=\left(\mathrm{S}_{\mathrm{CF}}+2 \times\right.$ $\left.\mathrm{S}_{\mathrm{CF} 2}\right) /\left(\mathrm{S}_{\mathrm{C}}+\mathrm{S}_{\mathrm{CF} 2}+\mathrm{S}_{\mathrm{CF}}\right)$, where $\mathrm{S}$ is the integrated intensities of the 13C NMR peaks.

\section{Material Characterization}

$\mathrm{X}$-ray powder diffraction (XRD) technique was employed to characterize phases of as-prepared materials, using $\mathrm{Cu}$ $\mathrm{K}_{\alpha}$ radiation (1.54178 ̊) on a Miniflex600 (Rigaku, Japan) instrument. XRD patterns were collected with a step of $0.0167^{\circ}$, and $20 \mathrm{~s}$ per step. ${ }^{13} \mathrm{C}$ and ${ }^{19} \mathrm{~F}$ magic angle spinning (MAS) NMR experiments were performed on Bruker $600 \mathrm{MHz}$ AVANCE III spectrometer using Hahn-echo pulse under the spinning frequencies of 12 and $60 \mathrm{kHz}$, respectively. Recycle delays of 60 and $20 \mathrm{~s}$ were applied for complete relaxation of excited magnetization for the acquisition of quantitative ${ }^{13} \mathrm{C}$ and ${ }^{19} \mathrm{~F}$ NMR spectra. The chemical shifts of ${ }^{13} \mathrm{C}$ and ${ }^{19} \mathrm{~F}$ were referenced to diamantine (38.6 ppm) and $\mathrm{LiF}$ (-204 ppm). X-ray photoelectron spectroscopy (XPS) of the samples was measured by an ESCALAB 250Xi spectrometer (Thermo Fisher). SEM images were performed on scanning electron microscopy (SEM) (ZEISS). The transmission electron microscopy (TEM) and high-resolution TEM (HRTEM) analysis were performed on Tecnai F20 (FEI, US), operating at $200 \mathrm{kV}$. Nitrogen adsorption/desorption isotherms and Brunauer-Emmett-Teller (BET) surface area were performed on a Quantachrome instrument Autosorb-iQ.

\section{Electrochemical Test}

The cathode was prepared by mixing 80 wt.\% fluorinated graphene, $10 \mathrm{wt} . \%$ acetylene black, and $10 \mathrm{wt} . \%$ poly (vinylidene fluoride) (PVDF). Aluminum disks were employed as current collectors and the active materials on the $\mathrm{Al}$ disks are between 1.5 and $2 \mathrm{mg} \mathrm{cm}^{-2}$. A lithium metal disk was used as a counter electrode, and electrolytes were $1 \mathrm{M} \mathrm{LiPF}_{6}$ dissolved in ethylene carbonate/dimethyl carbonate (1:1 volume ratio). Discharge tests were performed at various currents with a cutoff voltage of $1.5 \mathrm{~V}$ by a LAND CT2001A battery test system at $25^{\circ} \mathrm{C}$.

\section{RESULTS AND DISCUSSION}

\section{Electrochemical Performance}

It is well known that the fluorine content in fluorinated carbon significantly affects the electrochemical performance. A low fluorine content results in a good power density but relatively low energy density. To achieve excellent power densities with high energy densities, we prepared fluorinated graphene $\left(\mathrm{GF}_{\mathrm{x}}\right)$ with various $\mathrm{F}$ content and investigated the factors influencing the electrochemical performance. The $\mathrm{F}$ content in the $\mathrm{GF}_{\mathrm{x}}$ was controlled by varying the temperatures during the fluorination; for example, $\mathrm{GF}_{0.5}, \mathrm{GF}_{0.8}$, and $\mathrm{GF}_{1.1}$ were obtained at 400,430 , and $460^{\circ} \mathrm{C}$, respectively.

When the $\mathrm{x}$ in $\mathrm{GF}_{\mathrm{x}}$ equals 0.5, as shown in Figure 1A, the $\mathrm{GF}_{0.5}$ material delivered a capacity of $615 \mathrm{mAh} \mathrm{g}^{-1}$ (98.7\% of its theoretical capacity) with a discharge plateau at $\sim 2.9 \mathrm{~V}$ at a low current density of $20 \mathrm{~mA} \mathrm{~g}^{-1}\left(\sim 1 / 32 \mathrm{C}, 1 \mathrm{C}=623 \mathrm{~mA} \mathrm{~g}^{-1}\right.$ 

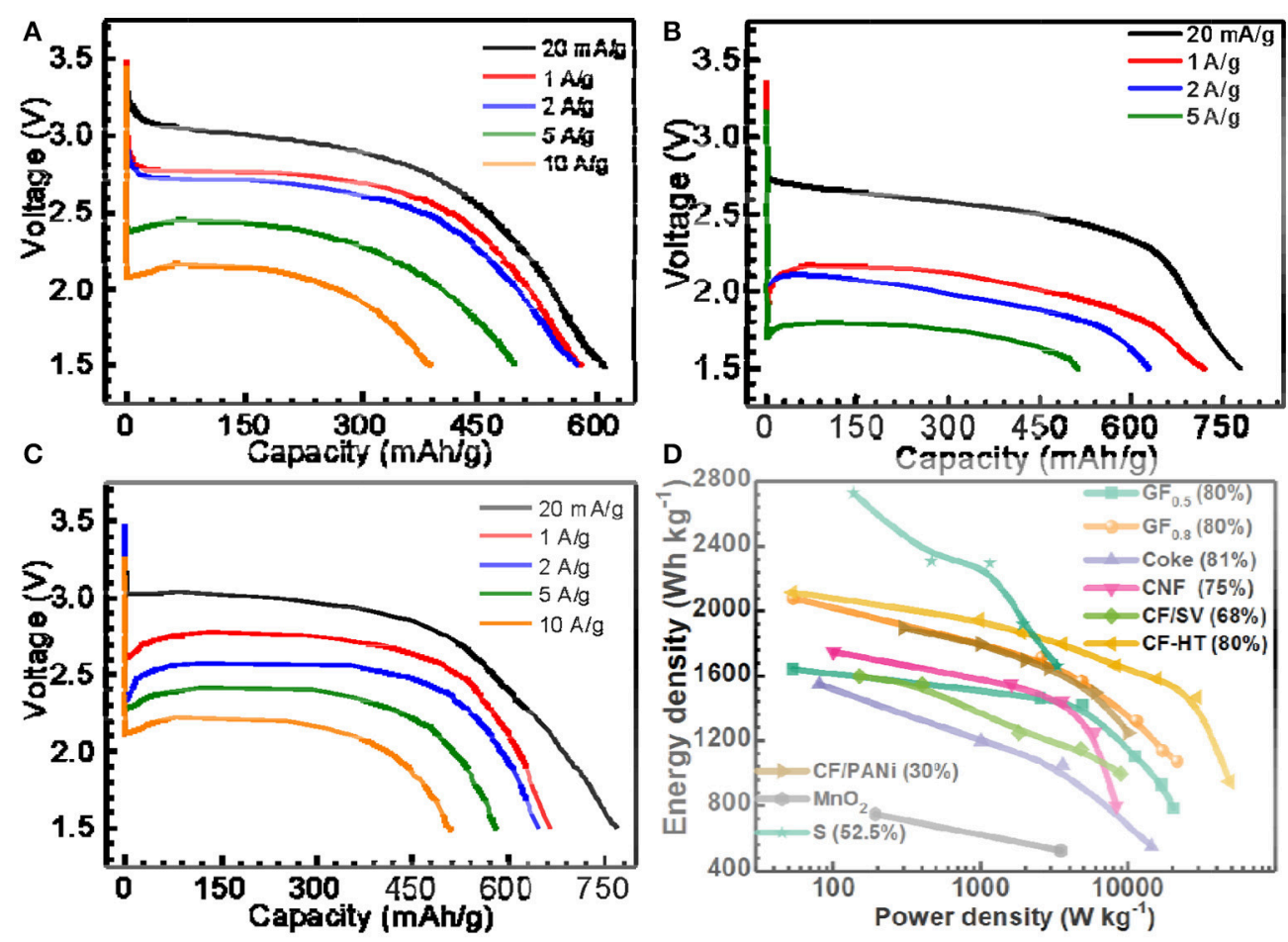

FIGURE 1 | Selected discharge curves of (A) $\mathrm{GF}_{0.5}$, (B) $\mathrm{GF}_{1.1}$, (C) GF 0.8 at different current densities, and (D) energy density vs. power density plots (Ragone plots) of the as-prepared GFx, typical fluorinated carbons, $\mathrm{MnO}_{2}$ and sulfur materials for primary Li batteries, in which the numbers in brackets indicate the mass percentages of active materials on the electrodes. CNF, SV, CF-HT, and PANi represent fluorinated carbon nanofiber, silver vanadate, fluorinated carbon with hydrothermal treatment, and polyaniline, respectively.

for $\mathrm{GF}_{0.5}$ ). When the current densities increased to $1 \mathrm{~A} \mathrm{~g}^{-1}$, the capacity of the $\mathrm{GF}_{0.5}$ decreased slightly to around $580 \mathrm{mAh} / \mathrm{g}$. Even if the current densities of 5 and $10 \mathrm{~A} \mathrm{~g}^{-1}$ were applied, the $\mathrm{GF}_{0.5}$ was still able to deliver 76.9 and $62.4 \%$, respectively, of its theoretical capacity, exhibiting very excellent rate capability. To the best of our knowledge, this is the best rate capability among the untreated fluorinated carbon materials reported in the literatures (Giraudet et al., 2006; Yazami et al., 2007; Zhang W. et al., 2009; Fulvio et al., 2011; Dubois et al., 2012).

With the impressive rate capability, the specific capacity of the $\mathrm{GF}_{0.5}$ is yet to be satisfied due to its low theoretical capacity (623 $\mathrm{mAh} \mathrm{g}^{-1}$ ). In contrast, the theoretical capacity of the $\mathrm{GF}_{1.1}$ is up to $896 \mathrm{mAh} \mathrm{g}^{-1}$. As shown in Figure $1 \mathbf{B}$, the $\mathrm{GF}_{1.1}$ depicts a capacity of $779 \mathrm{mAh} \mathrm{g}^{-1}$, which is 1.34 times of that of the $\mathrm{GF}_{0.5}$ at $20 \mathrm{~mA} \mathrm{~g}^{-1}$. However, at high current densities, the voltage plateaus of the $\mathrm{GF}_{1.1}$ decreased much more significantly compared with those of the $\mathrm{GF}_{0.5}$, suggesting much higher polarization for the $\mathrm{GF}_{1.1}$ material. For example, at $5 \mathrm{~A} \mathrm{~g}^{-1}$ the voltage plateau of the $\mathrm{GF}_{1.1}$ dropped to $1.77 \mathrm{~V}$ with a capacity of $511 \mathrm{mAh} \mathrm{g}^{-1}$ that is only $57 \%$ of its theoretical capacity. Furthermore, the $\mathrm{GF}_{1.1}$ could not work at $10 \mathrm{~A} \mathrm{~g}^{-1}$ at all.

The relatively poor rate capability of the $\mathrm{GF}_{1.1}$ is associated with its poor electrical conductivity, which needs to be addressed. Therefore, the way to gain high power densities while retaining high energy densities is to prepare $\mathrm{CF}_{\mathrm{X}}$ with high $\mathrm{F}$ content without compromising the electrical conductivity. To achieve this goal, instead of with complicated surface treatments (Groult et al., 2011; Reddy et al., 2013; Dai et al., 2014), we took the full advantage of high electrical conductivity of the semi-ionic $\mathrm{CF}$ bond in $\mathrm{CF}_{\mathrm{x}}$ (discussed in detail below). In other words, we made great effort to improve the $\mathrm{F}$ content within the limit without losing the semi-ionic bonds in the $\mathrm{CF}_{\mathrm{x}}$. With an optimal $\mathrm{F}$ content, the as-designed $\mathrm{GF}_{0.8}$ showed high capacity with excellent rate performance (Figure 1C). The specific capacity of the $\mathrm{GF}_{0.8}$ was $770 \mathrm{mAh} \mathrm{g}^{-1}, 97.8 \%$ of its theoretical capacity, at $20 \mathrm{~mA} \mathrm{~g}^{-1}$ (about $1 / 39 \mathrm{C}, 1 \mathrm{C}=788.2 \mathrm{~mA} \mathrm{~g}^{-1}$ for $\mathrm{GF}_{0.8}$ ). When the current densities enhanced to $10 \mathrm{~A} \mathrm{~g}^{-1}(\sim 12 \mathrm{C})$, the $\mathrm{GF}_{0.8}$ exhibited an extraordinary power density of $21,460 \mathrm{~W} \mathrm{~kg}^{-1}$ with a capacity of $511 \mathrm{mAh} \mathrm{g}^{-1}$, corresponding to $64.9 \%$ of the theoretical capacity and an energy density of 1,073 $\mathrm{Wh} \mathrm{kg}^{-1}$.

To understand the electrochemical performance of $\mathrm{GF}_{\mathrm{x}}$ electrode, we compared the kinetic properties of $\mathrm{GF}_{0.5}, \mathrm{GF}_{0.8}$, and $\mathrm{GF}_{1.1}$ by electrochemical impedance spectroscopy (EIS) measurement. To exclude the effect of conductive carbon, we prepared the electrodes with the $\mathrm{GF}_{\mathrm{x}}$ materials without addition of carbon black. In the absence of conductive carbon, however, the impedances of the fresh electrodes were too extremely high to obtain accurate results for comparison (Figure S1A) at opencircuit potentials. Therefore, $1 \%$ of the theoretical capacity was discharged to reasonably compare the impedances of the $\mathrm{CF}_{\mathrm{X}}$ 
electrodes. As illustrated in Figure $\mathrm{S} 1 \mathrm{~B}$, the charge-transfer resistance $\left(R_{c t}\right)$ of the $G_{1.1}$ is $2,500 \Omega$, much higher than that of the $\mathrm{GF}_{0.5}(\sim 1,400 \Omega)$ and the $\mathrm{GF}_{0.8}(\sim 1,600 \Omega)$.

Ragone plots were employed to depict the advanced electrochemical performance of the $\mathrm{GF}_{0.8}$ (Figure 1D), which is superior to most of the fluorinated carbon and other primary batteries in the literature (Table S1) (Giraudet et al., 2006; Lam and Yazami, 2006; Yazami et al., 2007; Zhang W. et al., 2009; Fulvio et al., 2011; Meduri et al., 2011; Dubois et al., 2012; Guérin et al., 2012; Wang et al., 2012; Adcock et al., 2013; Reddy et al., 2013; Dai et al., 2014, 2017; Sideris et al., 2014; Li and Feng, 2015; Liang et al., 2015; Zhang et al., 2015; Li et al., 2016; Zhu et al., 2017). For example, Lam and Yazami prepared fluorinated coke materials, which showed a maximum power density of about $14,400 \mathrm{~W} \mathrm{~kg}^{-1}$ with energy density of $500 \mathrm{Wh}$ $\mathrm{kg}^{-1}$ (Lam and Yazami, 2006). Sulfur material typically display greater energy density but much lower power density due to awfully low electrical conductivity $\left(\sim 10^{-30} \mathrm{~S} \mathrm{~cm}^{-1}\right)$, for which a large amount of carbon has to been applied during electrode preparation (Manthiram et al., 2015; Pang et al., 2015).

\section{Bonding Characteristics of $\mathrm{GF}_{\mathbf{x}}$ Materials}

As mentioned above, we achieve high energy densities with excellent power densities by the full use of the advantage of semiionic $\mathrm{C}$-F bonds in the $\mathrm{CF}_{\mathrm{X}}$. Ionic, semi-ionic, and covalent $\mathrm{C}-\mathrm{F}$ bonds are the three types of $\mathrm{C}-\mathrm{F}$ bonds in the $\mathrm{CF}_{\mathrm{x}}$. Ionic $\mathrm{C}$ $\mathrm{F}$ bonds are typically only formed when $\mathrm{x}$ in $\mathrm{CF}_{\mathrm{X}}$ is very small (e.g., < 0.05 for graphite; Amine and Nakajima, 1993; Nansé et al., 1997; Giraudet et al., 2006), which is not useful in $\mathrm{CF}_{\mathrm{X}} / \mathrm{Li}$ batteries because of the very low capacity. Covalent $\mathrm{C}-\mathrm{F}$ bonds possess the characteristics of the $\mathrm{sp}^{3} \mathrm{C}$ with the $\mathrm{F}-\mathrm{C}-\mathrm{C}$ angles larger than $90^{\circ}$ and the neighboring $\mathrm{C}-\mathrm{C}$ bond length of $\sim 0.153 \mathrm{~nm}$ (Sato et al., 2004; Figure S2A). High covalent C-F ratio may ruin the conductive network of the conjugated double bonds, exhibiting insulating property (electrical conductivity lower than $10^{-15} \mathrm{~S}$ $\mathrm{cm}^{-1}$; Sato et al., 2004).

In contrast, semi-ionic C-F bonds are essentially covalent, with which, however, the conjugated $\mathrm{C}-\mathrm{C}$ bonds are preserved between carbon atoms unbounding to fluorine with the F-C-C angle of $90^{\circ}$ and the neighboring $\mathrm{C}-\mathrm{C}$ bond length of $\sim 0.14 \mathrm{~nm}$ (Sato et al., 2004; Figure S2B). Unlike what happens in the presence of covalent C-F bonds, with semi-ionic C-F bonds and a certain proportion of $\mathrm{sp}^{2} \mathrm{C}, \mathrm{CF}_{\mathrm{x}}$ may have high electronic conductivity, for example, the electronic conductivity of $\mathrm{C}_{\mathrm{x}} \mathrm{F}$ with $\mathrm{x}$ around two ranged between $5 \times 10^{-8}$ and $1 \times 10^{-7} \mathrm{~S}$ $\mathrm{cm}^{-1}$ (Sato et al., 2004). In a word, the semi-ionic C-F bonds do not significantly degrade the electrical conductivity of the $\mathrm{CF}_{\mathrm{X}}$ (Mallouk and Bartlett, 1983; Amine and Nakajima, 1993; Sato et al., 2004; Zhang W. et al., 2010), which can be employed to gain high power densities with high energy densities.

\section{Solid-State ${ }^{19} \mathrm{~F}$ and ${ }^{13} \mathrm{C}$ NMR Spectra}

${ }^{19} \mathrm{~F}$ NMR spectra were employed to distinguish covalent and semi-ionic C-F bonds. Figure $2 \mathrm{~A}$ shows that the ${ }^{19} \mathrm{~F}$ MAS NMR spectra acquired at a spinning frequency of $60 \mathrm{kHz}$, in which the ${ }^{19} \mathrm{~F}$ resonances consist of three parts. Resonance peaks located between -80 and -135 ppm belong to the signal of $\mathrm{CF}_{2}$ groups.
Resonance peaks located between -140 and -180 ppm were assigned to the signal of the semi-ionic CF group, while the peaks located between -185 and -189 ppm were assigned to the signal of the covalent CF group (Panich et al., 1997; Krawietz and Haw, 1998; Giraudet et al., 2007; Leifer et al., 2010; Ahmad et al., 2013).

The semi-ionic C-F bond ratios in the $\mathrm{GF}_{\mathrm{X}}$ were determined by fitting of ${ }^{19} \mathrm{~F}$ NMR spectra (Figure $\mathrm{S} 3$ ). As shown in Figure 2C, the semi-ionic bond ratio in $\mathrm{GF}_{0.5}$ is $38.5 \%$, which slightly decreases to $37.7 \%$ when the $\mathrm{x}$ in $\mathrm{GF}_{\mathrm{x}}$ increases to 0.8 . Beyond that point, the semi-ionic bond ratio in the $\mathrm{GF}_{\mathrm{x}}$ dramatically dropped (e.g., $16.1 \%$ in $\mathrm{GF}_{1.1}$ ), which is consistent with the facts that the rate capability of the $\mathrm{GF}_{0.8}$ is similar with that of the $\mathrm{GF}_{0.5}$, but much better than that of the $\mathrm{GF}_{1.1}$. For example, at $5 \mathrm{~A} \mathrm{~g}^{-1}$, the energy densities of the $\mathrm{GF}_{0.5}, \mathrm{GF}_{0.8}$, and $\mathrm{GF}_{1.1}$ are $10,856,11,352$, and $898 \mathrm{Wh} \mathrm{kg}^{-1}$, respectively (Figure 1).

Another possible reason for poor electrical conductivity related to the low semi-ionic $\mathrm{C}$-F bond ratio is the high $\mathrm{F}$ content resulting in low content of the $\mathrm{sp}^{2}$ hybridized C. Figure $2 \mathbf{B}$ exhibits the ${ }^{13} \mathrm{C}$ NMR spectra, in which the resonance peaks at around 130,111, and $87 \mathrm{ppm}$ are associated with the $\mathrm{sp}^{2}$ $\mathrm{C}, \mathrm{CF}_{2}$, and $\mathrm{CF}$, respectively. Their contents were calculated by fitting the peaks (Figure S4). The $\mathrm{sp}^{2} \mathrm{C}$ contents in the $\mathrm{GF}_{0.5}, \mathrm{GF}_{0.8}$, and $\mathrm{GF}_{1.1}$ are calculated to be $49.8,22.8$, and $3.4 \%$, respectively (Figure 2D). When the $\mathrm{sp}^{2} \mathrm{C}$ content goes down to too low value (e.g., $3.4 \%$ in the $\mathrm{GF}_{1.1}$ ), the electrical conductivity is compromised (Yue et al., 2013), resulting in a poor rate capability.

Based on the ${ }^{19} \mathrm{~F}$ and ${ }^{13} \mathrm{C}$ NMR analysis, we can conclude that with the increasing $\mathrm{F}$ content in $\mathrm{GF}_{\mathrm{X}}$, the $\mathrm{sp}^{2} \mathrm{C}$ ratio decreases while the semi-ionic $\mathrm{C}$-F bond ratio remains unchanged until the critical $\mathrm{x}$ of 0.8 , beyond which the electron-transfer ability of $\mathrm{sp}^{2}$ $\mathrm{C}$ is compromised. This matches very well the electrochemical performance of $\mathrm{GF}_{0.5}, \mathrm{GF}_{0.8}$, and $\mathrm{GF}_{1.1}$, namely, the $\mathrm{GF}_{0.5}$ and $\mathrm{GF}_{1.1}$ depicted high power densities and high capacities, respectively, but the $\mathrm{GF}_{0.8}$ exhibited the optimal electrochemical performance $\left(21,460 \mathrm{~W} \mathrm{~kg}^{-1}\right.$ and $\left.1,073 \mathrm{kWh} \mathrm{kg}^{-1}\right)$.

\section{XPS Spectra}

Semi-ionic C-F bond ratios in $\mathrm{CF}_{\mathrm{x}}$ also have been analyzed using $\mathrm{X}$-ray photoelectron spectroscopy (XPS) spectra (Doniach and Sunjic, 1970; Tressaud et al., 1996; Nansé et al., 1997; Leiro et al., 2003; Park et al., 2008). We therefore conducted XPS analysis for our $\mathrm{GF}_{\mathrm{x}}$ materials for comparison. As shown in Figure 3A, the carbon in the RGO was mainly composed of $\mathrm{C}=\mathrm{C} \mathrm{sp}^{2}$ bonds $(284.4 \mathrm{eV})$ and minor bonds $\mathrm{C}-\mathrm{O}-\mathrm{C}(\sim 286.5 \mathrm{eV})$ and $\mathrm{O}-\mathrm{C}=\mathrm{O}$ $\left(\sim 288.6 \mathrm{eV}\right.$ ). In the $\mathrm{GF}_{0.5}$ (Figure 3B), the binding energies at 288.0 and $288.8 \mathrm{eV}$ were assigned to the semi-ionic and the covalent CF bonds, respectively (Tressaud et al., 1996; Nansé et al., 1997; Wang et al., 2014).

In contrast, the semi-ionic C-F bonds were barely detected by XPS C1s spectra for the $\mathrm{GF}_{0.8}$ and $\mathrm{GF}_{1.1}$ (Figures 3C,D), which are consistent with the results from the XPS F1s spectra (Figure $\mathrm{S} 5$ ); no semi-ionic $\mathrm{C}-\mathrm{F}$ bond was detected in the $\mathrm{GF}_{0.8}$ and $\mathrm{GF}_{1.1}$. In other words, the $\mathrm{C}-\mathrm{F}$ bond on the surface of the $\mathrm{GF}_{0.8}$ and $\mathrm{GF}_{1.1}$ materials were mainly covalent. Apparently, these results are inconsistent with those from NMR, where the semi-ionic C-F ratios in $\mathrm{GF}_{0.8}$ and $\mathrm{GF}_{1.1}$ are much higher. This is because that 

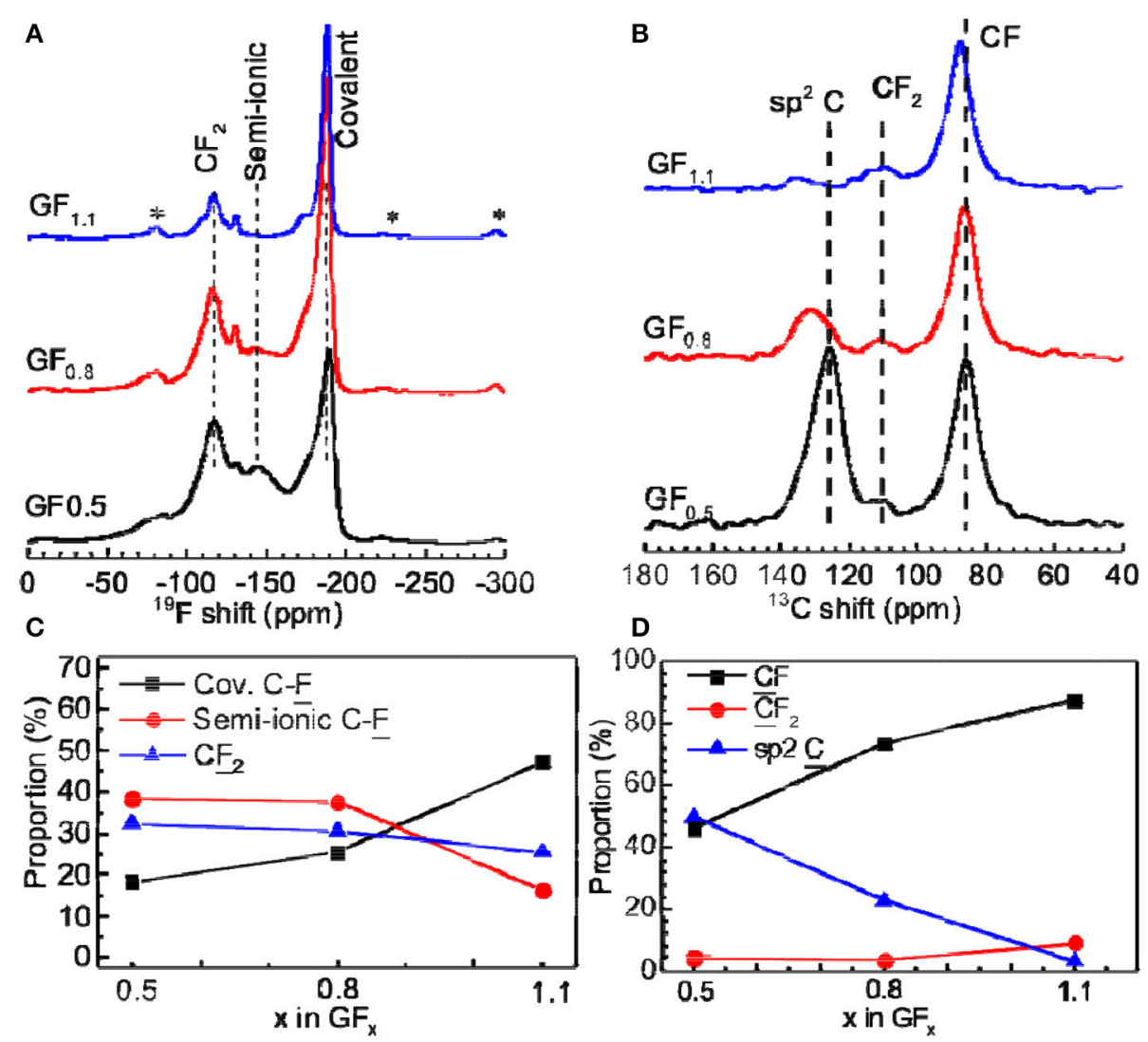

FIGURE 2 | (A) ${ }^{19} \mathrm{~F}$ and (B) ${ }^{13} \mathrm{C}$ MAS NMR spectra of GFX acquired at spinning frequencies of 60 and $12 \mathrm{kHz}$, respectively. The asterisks indicate the spinning sidebands. (C,D) Integral area proportions of fluorine and carbon with different bonding properties from ${ }^{19} \mathrm{~F}$ and ${ }^{13} \mathrm{C}$ NMR spectra, respectively.

the surface of the $\mathrm{GF}_{\mathrm{x}}$ is subjected to more attack than the bulk during fluorination, resulting in higher fluorinating levels on the $\mathrm{GF}_{\mathrm{x}}$ surface than in the bulk. The semi-ionic $\mathrm{C}-\mathrm{F}$ in $\mathrm{GF}_{0.8}$ and $\mathrm{GF}_{1.1}$ can be detected by NMR but not by XPS because that is for surface analysis while the former obtains bulk information. As a conclusion, NMR is more suitable for analyzing semi-ionic C-F bond ratio in $\mathrm{CF}_{\mathrm{x}}$ than XPS (Figures 3E,F).

Besides the semi-ionic C-F bond ratio, other factors that may influence the electrochemical performance of the $\mathrm{GF}_{\mathrm{x}}$ were also investigated, including structure, morphology, and surface area.

\section{XRD Patterns and Morphology Features XRD Patterns and TEM Images}

XRD patterns of fluorinated graphene materials were shown in Figure S6. Two peaks centered at around 25.4 and $43.2^{\circ}$ were observed for the RGO, which correspond with the 002 and 100 reflections of graphitic carbon, respectively. After fluorination, the 002 reflection decreased significantly while a new peak at $\sim 15^{\circ}$ developed for the three fluorinated samples, which may be assigned to the 001 plane of fluorinated phase (Hamwi, 1996; Meduri et al., 2013) or the expanded 002 plane (Zhang et al., 2015). The layer thickness of the RGO increased from $\sim 0.4$ to $\sim 0.6 \mathrm{~nm}$ after fluorination as indicated by HRTEM (Figures S7-S9), which is in accordance with results from XRD patterns (Figure S6). Note also that the 100 reflections shifted to lower angle with increasing fluorination levels, indicating an increasing $\mathrm{C}-\mathrm{C}$ in-plane length, which is consistent with the trend of fluorinated graphite (Guérin et al., 2004). Theoretically, increased interplanar distances in the $\mathrm{GF}_{\mathrm{x}}$ may facilitate the intercalation of lithium ions. However, considering the fact that $\mathrm{GF}_{1.1}$ shows a poor rate capability than the $\mathrm{GF}_{0.8}$, the increasing of $d$-spacing does not offer enough help the $\mathrm{GF}_{1.1}$ to gain excellent power density.

\section{SEM Images}

Figure 4 showed the SEM images of the RGO and $\mathrm{GF}_{\mathrm{x}}$ materials, indicating their secondary particle sizes larger than 10 microns due to the aggregation of GO upon drying. Interestingly, compared with pristine RGO, the fluorinated graphene materials exhibit clear lamellar architectures that were marked by the yellow arrows in Figures $\mathbf{4 d , f , h}, \mathbf{h}$; especially in $\mathrm{GF}_{0.8}$ and $\mathrm{GF}_{1.1}$, some fluorinated graphene layers seem to be peeled off. Although fluorination introduces $\mathrm{F}$ into the interlayers of $\mathrm{C}$, the $d$-spacing of 002 facet only expands from $\sim 0.33$ to $\sim 0.6 \mathrm{~nm}$. Therefore, we believe the splitting of graphene layers is not due to the $\mathrm{F}$ expansion, but to the attack by the fluorinating gas during the fluorination at high temperatures. As a matter of fact, the $\mathrm{GF}_{1.1}$ 

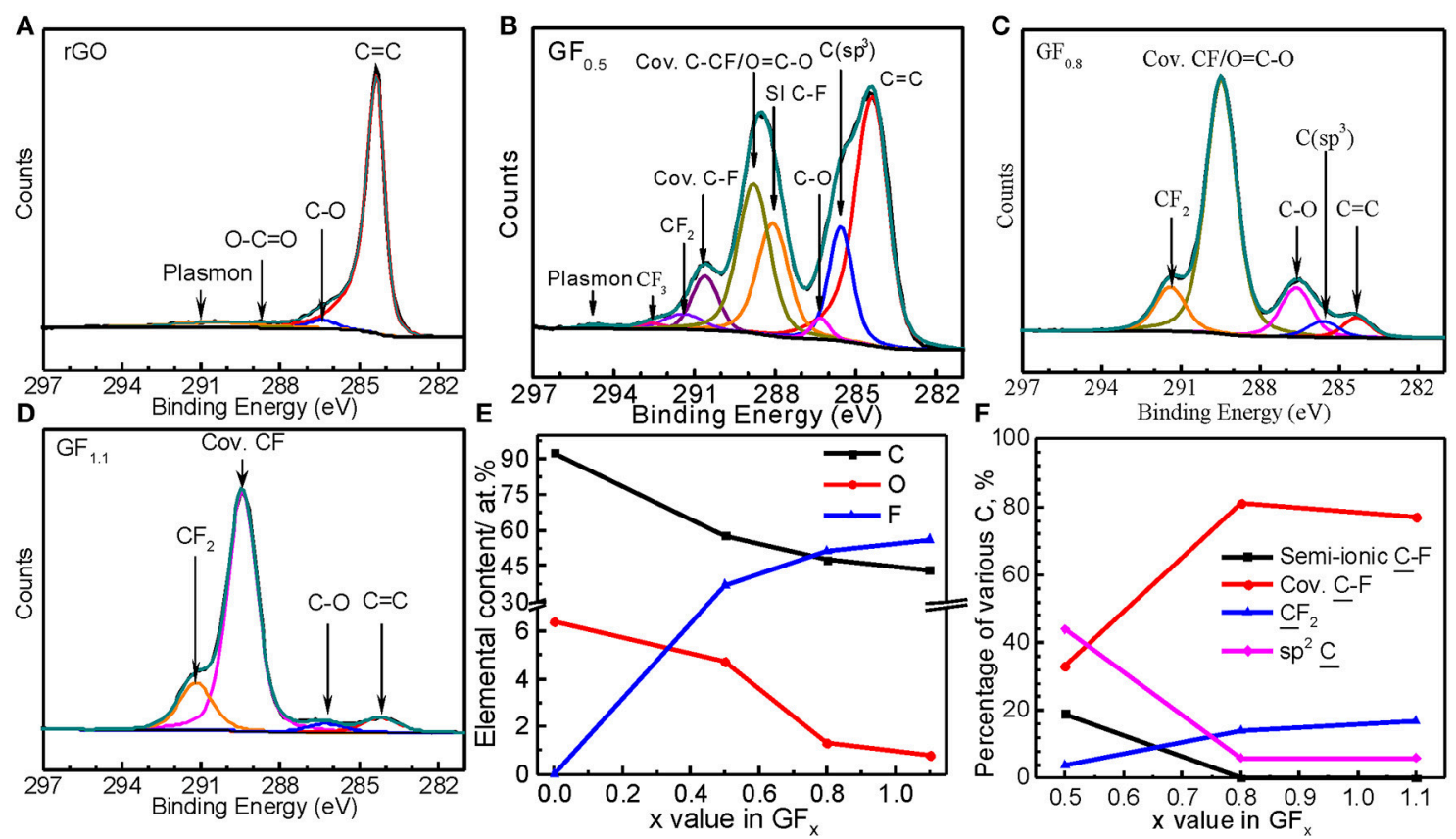

FIGURE 3 | XPS C1s spectra of (A) RGO, (B) $\mathrm{GF}_{0.5}$, (C) $\mathrm{GF}_{0.8}$, and (D) GF 1.1 , and quantitative analysis results from XPS survey spectra (E) and C1s spectra (F).

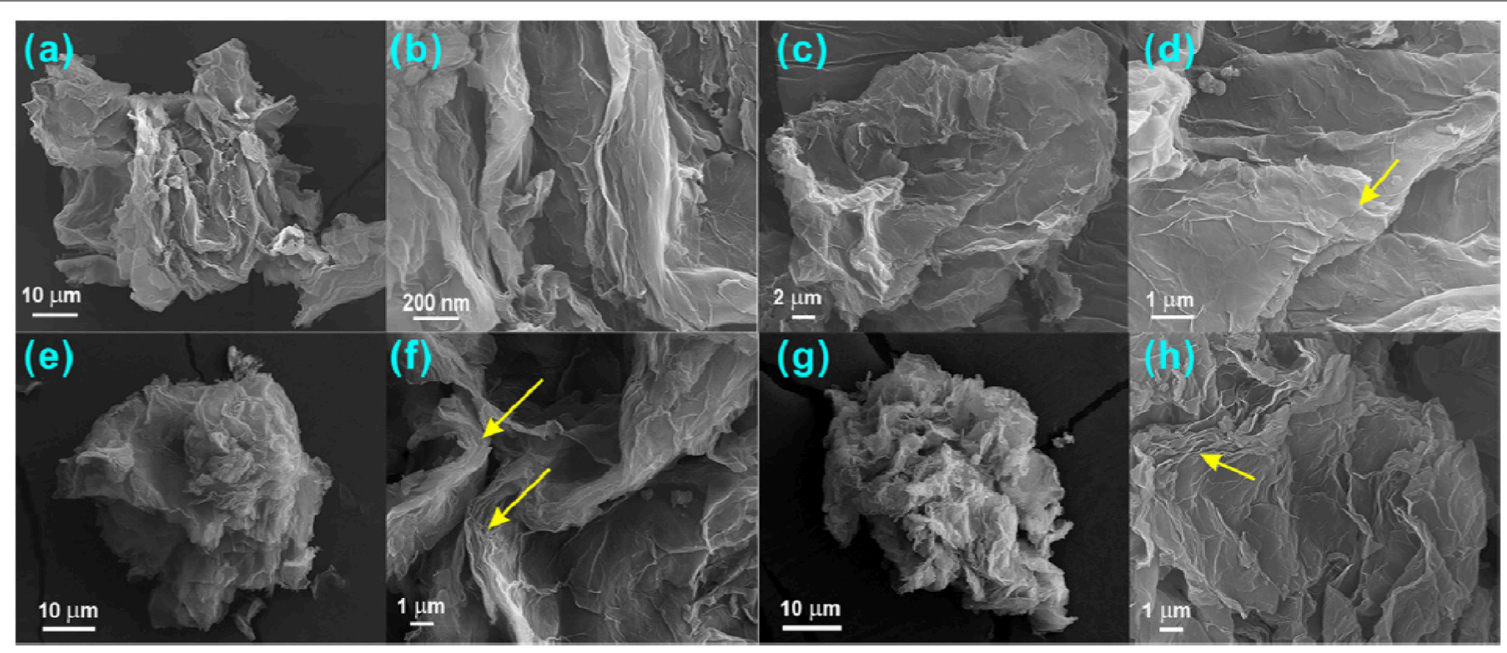

FIGURE 4 | SEM images of (a,b) RGO, (c,d) $\mathrm{GF}_{0.5}, \mathbf{( e , f )} \mathrm{GF}_{0.8}$, and $\mathbf{( g , h )} \mathrm{GF}_{1.1}$. The yellow arrows indicate the lamellar structure of fluorinated graphenes.

was stripped more severely than the $\mathrm{GF}_{0.8}$ and much more than the $\mathrm{GF}_{0.5}$, which agrees well with their preparation temperatures. The splitting of graphene layers might facilitate the diffusion of solvated lithium ions compared with other types of fluorinated carbon materials (Meduri et al., 2013), thereby enhancing the rate capability of $\mathrm{GF}_{\mathrm{x}}$. However, the power density of the $\mathrm{GF}_{1.1}$ is poorer than that of the $\mathrm{GF}_{0.8}$, which is inconsistent with the lager expanded spaces. Therefore, the effect of morphology change on the rate performance is inferior to the semi-ionic $\mathrm{C}-\mathrm{F}$ bond ratio in the $\mathrm{GF}_{\mathrm{x}}$.

\section{BET Results}

During fluorination, the surface area may change, thereby contributing to the improved rate performance. Therefore, the specific surface areas of the pristine RGO and the fluorinated graphene materials were analyzed using BrunauerEmmett-Teller (BET) method. Figure 5A exhibits the nitrogen adsorption-desorption isotherm; accordingly, the BET specific surface areas for the RGO, $\mathrm{GF}_{0.5}, \mathrm{GF}_{0.8}$, and $\mathrm{GF}_{1.1}$ were measured to be $70.2,152.4,215.8,238.6 \mathrm{~m}^{2} \mathrm{~g}^{-1}$, respectively. The relatively small specific area of the RGO is due to the relatively thick 

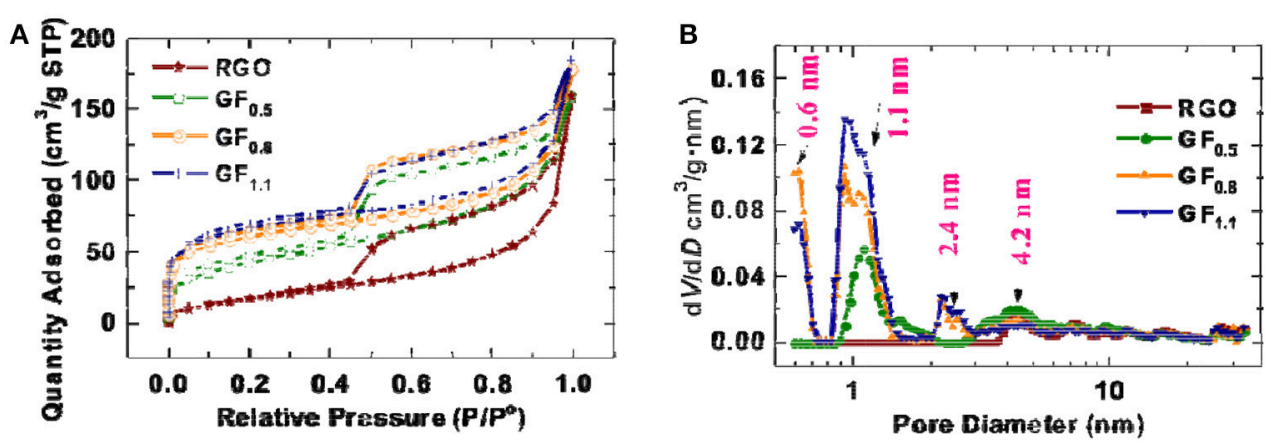

FIGURE 5 | (A) Nitrogen adsorption-desorption isotherm and (B) pore size distribution of pristine RGO and the fluorinated graphene materials.

graphene, which is confirmed by HRTEM (Figure S7). The thickness of the RGO is up to 20 layers from the HRTEM observation.

After fluorination, the specific area increased, which is consistent with the SEM observation, in which the fluorinated graphenes exhibit more lamellar architectures, compared with the pristine RGO (Figure 5). The pore sizes of the as-prepared fluorinated graphenes were analyzed based on a quenched solid density functional theory (QSDFT) kernel applied to the adsorption branch using a slit/cylindrical pore model (Ravikovitch and Neimark, 2006; Gor et al., 2012). As shown in Figure 5B, the RGO possesses mesopores $(\sim 4.2 \mathrm{~nm})$ without any micropores. In contrast, after fluorination, micropores were developed at $1.1 \mathrm{~nm}$ for the $\mathrm{GF}_{0.5}$ and an additional micropore size was observed at $0.6 \mathrm{~nm}$ for the $\mathrm{GF}_{0.8}$ and $\mathrm{GF}_{1.1}$. Although the increased pores and surface areas might facilitate lithium ion transfer, the higher surface the as-obtained fluorinated graphenes did not result in a better rate capability. Therefore, the surface area of the fluorographenes is not the determining factor affecting the power densities of the fluorinated graphenes.

\section{CONCLUSIONS}

Fluorinated graphenes were prepared using one-step gas fluorination of RGO at elevated temperatures. The impacting factors, including semi-ionic $\mathrm{C}-\mathrm{F}$ ratio, $\mathrm{sp}^{2} \mathrm{C}$ content, structure, morphology, and specific surface area are investigated to gain fluorinated graphenes with high power densities and high energy densities. The semi-ionic C-F ratio in the fluorinated graphene shows the most critical influence on achievement of high rate performance. Thus, by manipulating the semi-ionic $\mathrm{C}-\mathrm{F}$ proportion in the fluorinated graphene by temperature control, we obtain the optimal $\mathrm{x}$ of 0.8 in $\mathrm{GF}_{\mathrm{x}}$; the $\mathrm{GF}_{0.8}$ exhibited a

\section{REFERENCES}

Adcock, J. L., Fulvio, P. F., and Dai, S. (2013). Towards the selective modification of soft-templated mesoporous carbon materials by elemental fluorine for energy storage devices. J. Mater. Chem. A 1, 9327-9331. doi: 10.1039/c3ta10700k

Ahmad, Y., Dubois, M., Guérin, K., Hamwi, A., Fawal, Z., Kharitonov, A. P., et al. (2013). NMR and NEXAFS study of various graphite fluorides. J. Phys. Chem. C 117, 13564-13572. doi: 10.1021/jp401579u high energy density of $1,073 \mathrm{Wh} \mathrm{kg}^{-1}$ and an excellent density of $21,460 \mathrm{~W} \mathrm{~kg}^{-1}$ at a high current density of $10 \mathrm{~A} \mathrm{~g}^{-1}$ (about $12 \mathrm{C}$ rate). Compared with those using additional steps (such as $\mathrm{C}$ coating and hydrothermal treatment) to improve the rate performance of as-obtained $\mathrm{CF}_{\mathrm{X}}$, we offer a one-step approach to obtain high energy densities without compromising power densities for preparation of fluorinated carbon, showing very promising practical application.

\section{AUTHOR CONTRIBUTIONS}

The work cannot be completed without kind cooperation of all authors. GZ: Acquired and analyzed the NMR and XPS data; HC: Carried out the material preparation and electrochemical test; $\mathrm{XH}$ and HC: Carried out and analyzed the SEM, TEM, and BET analysis; GZ and XH: Wrote the paper and all authors discussed the results and revised the manuscript; HY, GZ, HC, and XH: Proposed the research; HY and CL: Attained the main financial support for the research and supervised all the experiments.

\section{ACKNOWLEDGMENTS}

The study was supported by the National Natural Science Foundation of China (21503232 and 21603231); Fujian Natural Science Foundation of China (2060203); and Xiamen Science and Technology Planning Project of China (3502Z20161246 and 3502Z20172030).

\section{SUPPLEMENTARY MATERIAL}

The Supplementary Material for this article can be found online at: https://www.frontiersin.org/articles/10.3389/fchem. 2018.00050/full\#supplementary-material

Amine, K., and Nakajima, T. (1993). A new stage-2 graphite intercalation compound: $\mathrm{C}_{2} \mathrm{~F}$ with nestled fluorine atoms. Carbon 31, 553-556. doi: 10.1016/0008-6223(93)90108-M

Dai, Y., Cai, S., Wu, L., Yang, W., Xie, J., Wen, W., et al. (2014). Surface modified $\mathrm{CF}_{\mathrm{X}}$ cathode material for ultrafast discharge and high energy density. J. Mater. Chem. A 2, 20896-20901. doi: 10.1039/C4TA05492J

Dai, Y., Fang, Y., Cai, S., Wu, L., Yang, W., Yan, H., et al. (2017). Surface modified pinecone shaped hierarchical structure fluorinated mesocarbon microbeads for 
ultrafast discharge and improved electrochemical performances. J. Electrochem. Soc. 164, A1-A7. doi: 10.1149/2.0451614jes

Damien, D., Sudeep, P. M., Narayanan, T. N., Anantharaman, M. R., Ajayan, P. M., and Shaijumon, M. M. (2013). Fluorinated graphene based electrodes for high performance primary lithium batteries. RSC Adv. 3, 25702-25706. doi: $10.1039 / \mathrm{c} 3 \mathrm{ra} 45377 \mathrm{~d}$

Doniach, S., and Sunjic, M. (1970). Many-electron singularity in X-ray photoemission and X-ray line spectra from metals. J. Phys. C Solid State Phys. 3, 285-291.

Dubois, M., Guérin, K., Zhang, W., Ahmad, Y., Hamwi, A., Fawal, Z., et al. (2012). Tuning the discharge potential of fluorinated carbon used as electrode in primary lithium battery. Electrochim. Acta 59, 485-491. doi: 10.1016/j.electacta.2011.11.015

Feng, W., Long, P., Feng, Y., and Li, Y. (2016). Two-dimensional fluorinated graphene: synthesis, structures, properties and applications. Adv. Sci. 3:1500413. doi: 10.1002/advs.201500413

Fulvio, P. F., Brown, S. S., Adcock, J., Mayes, R. T., Guo, B., Sun, X.-G., et al. (2011). Low-temperature fluorination of soft-templated mesoporous carbons for a high-power lithium/carbon fluoride battery. Chem. Mater. 23, 4420-4427. doi: $10.1021 / \mathrm{cm} 2012395$

Giraudet, J., Delabarre, C., Guérin, K., Dubois, M., Masin, F., and Hamwi, A. (2006). Comparative performances for primary lithium batteries of some covalent and semi-covalent graphite fluorides. J. Power Sources 158, 1365-1372. doi: 10.1016/j.jpowsour.2005.10.020

Giraudet, J., Dubois, M., Guérin, K., Delabarre, C., Hamwi, A., and Masin, F. (2007). Solid-state NMR study of the post-fluorination of $\left(\mathrm{C}_{2.5} \mathrm{~F}\right) \mathrm{n}$ fluorine-GIC. J. Phys. Chem. B 111, 14143-14151. doi: 10.1021/jp076170g

Gor, G. Y., Thommes, M., Cychosz, K. A., and Neimark, A. V. (2012). Quenched solid density functional theory method for characterization of mesoporous carbons by nitrogen adsorption. Carbon 50, 1583-1590. doi: 10.1016/j.carbon.2011.11.037

Groult, H., Julien, C. M., Bahloul, A., Leclerc, S., Briot, E., and Mauger, A. (2011). Improvements of the electrochemical features of graphite fluorides in primary lithium battery by electrodeposition of polypyrrole. Electrochem. Commun. 13, 1074-1076. doi: 10.1016/j.elecom.2011. 06.038

Guérin, K., Dubois, M., Houdayer, A., and Hamwi, A. (2012). Applicative performances of fluorinated carbons through fluorination routes: a review. J. Fluor. Chem. 134, 11-17. doi: 10.1016/j.jfluchem.2011.06.013

Guérin, K., Pinheiro, J. P., Dubois, M., Fawal, Z., Masin, F., Yazami, R., et al. (2004). Synthesis and characterization of highly fluorinated graphite containing sp ${ }^{2}$ and $\mathrm{sp}^{3}$ carbon. Chem. Mater. 16, 1786-1792. doi: 10.1021/cm0 $34974 \mathrm{c}$

Hamwi, A. (1996). Fluorine reactivity with graphite and fullerenes. fluoride derivatives and some practical electrochemical applications. J. Phys. Chem. Solids 57, 677-688. doi: 10.1016/0022-3697(95)00332-0

Hummers, W. S., and Offeman, R. E. (1958). Preparation of graphitic oxide. J. Am. Chem. Soc. 80, 1339-1339. doi: 10.1021/ja01539a017

Krawietz, T. R., and Haw, J. F., (1998). Characterization of poly(carbon monofluoride) by ${ }^{19} \mathrm{~F}$ and ${ }^{19} \mathrm{~F}$ to ${ }^{13} \mathrm{C}$ cross polarization MAS NMR spectroscopy. Chem. Commun. 2151-2152. doi: 10.1039/a803252a

Lam, P., and Yazami, R. (2006). Physical characteristics and rate performance of $\left(\mathrm{CF}_{\mathrm{x}}\right)_{\mathrm{n}}(0.33<\mathrm{x}<0.66)$ in lithium batteries. J. Power Sources 153, 354-359. doi: 10.1016/j.jpowsour.2005.05.022

Leifer, N. D., Johnson, V. S., Ben-Ari, R., Gan, H., Lehnes, J. M., Guo, R., et al. (2010). Solid-state NMR studies of chemically lithiated $\mathrm{CF}_{\mathrm{x}}$. J. Electrochem. Soc. 157, A148-A154. doi: 10.1149/1.3267042

Leiro, J. A., Heinonen, M. H., Laiho, T., and Batirev, I. G. (2003). Core-level XPS spectra of fullerene, highly oriented pyrolitic graphite, and glassy carbon. J. Electron. Spectrosc. Relat. Phenom. 128, 205-213. doi: $10.1016 / S 0368-2048(02) 00284-0$

Li, L., Zhu, L., Pan, Y., Lei, W., Ma, Z., Li, Z., et al. (2016). Integrated polyaniline-coated $\mathrm{CF}_{\mathrm{x}}$ cathode materials with enhanced electrochemical capabilities for Li/CF primary battery. Int. J. Electrochem. Sci. 11, 6838-6847. doi: $10.20964 / 2016.08 .41$

Li, Y., and Feng, W. (2015). The tunable electrochemical performances of carbon fluorides/manganese dioxide hybrid cathodes by their arrangements. J. Power Sources 274, 1292-1299. doi: 10.1016/j.jpowsour.2014.10.150
Liang, X., Hart, C., Pang, Q., Garsuch, A., Weiss, T., and Nazar, L. F. (2015). A highly efficient polysulfide mediator for lithium-sulfur batteries. Nat. Commun. 6:5682. doi: $10.1038 /$ ncomms6682

Mallouk, T., and Bartlett, N. (1983). Reversible intercalation of graphite by fluorine: a new bifluoride, C12HF2, and graphite fluorides, $\mathrm{CxF}(5>\mathrm{x}>2)$. J. Chem. Soc. Chem. Commun. 103-105.

Manthiram, A., Chung, S. H., and Zu, C. (2015). Lithium-sulfur batteries: progress and prospects. Adv. Mater. Weinheim. 27, 1980-2006. doi: 10.1002/adma.201405115

Matsuo, Y., and Nakajima, T. (1996). Electrochemical properties of fluorinated fullerene $\mathrm{C}_{60}$. Electrochim. Acta 41, 15-19. doi: 10.1016/0013-4686(95)00288-P

Meduri, P., Chen, H., Chen, X., Xiao, J., Gross, M. E., Carlson, T. J., et al. (2011). Hybrid $\mathrm{CF}_{\mathrm{x}}-\mathrm{Ag}_{2} \mathrm{~V}_{4} \mathrm{O}_{11}$ as a high-energy, power density cathode for application in an underwater acoustic microtransmitter. Electrochem. Commun. 13, 1344-1348. doi: 10.1016/j.elecom.2011.08.006

Meduri, P., Chen, H., Xiao, J., Martinez, J. J., Carlson, T., Zhang, J.-G., et al. (2013). Tunable electrochemical properties of fluorinated graphene. J. Mater. Chem. A 1, 7866-7869. doi: 10.1039/c3ta11710c

Mickelson, E. T., Huffman, C. B., Rinzler, A. G., Smalley, R. E., Hauge, R. H., and Margrave, J. L. (1998). Fluorination of single-wall carbon nanotubes. Chem. Phys. Lett. 296, 188-194. doi: 10.1016/S0009-2614(98)01026-4

Nakajima, T., Gupta, V., Ohzawa, Y., Koh, M., Singh, R. N., Tressaud, A., et al. (2002). Electrochemical behavior of plasma-fluorinated graphite for lithium ion batteries. J. Power Sources 104, 108-114. doi: 10.1016/S0378-7753(01)00895-3

Nansé, G., Papirer, E., Fioux, P., Moguet, F., and Tressaud, A. (1997). Fluorination of carbon blacks: an $\mathrm{x}$-ray photoelectron spectroscopy study: I. A literature review of XPS studies of fluorinated carbons. XPS investigation of some reference compounds. Carbon 35, 175-194. doi: 10.1016/S0008-6223(96)00095-4

Pang, Q., Liang, X., Kwok, C. Y., and Nazar, L. F. (2015). Review-The importance of chemical interactions between sulfur host materials and lithium polysulfides for advanced lithium-sulfur batteries. J. Electrochem. Soc. 162, A2567-A2576. doi: 10.1149/2.0171514jes

Panich, A. M., Nakajima, T., and Goren, S. D. (1997). ${ }^{19}$ F NMR study of C-F bonding and localization effects in fluorine-intercalated graphite. Chem. Phys. Lett. 271, 381-384. doi: 10.1016/S.0009-2614(97)00450-8

Park, S., An, J., Piner, R. D., Jung, I., Yang, D., Velamakanni, A., et al. (2008). Aqueous suspension and characterization of chemically modified graphene sheets. Chem. Mater. 20, 6592-6594. doi: 10.1021/cm801932u

Ravikovitch, P. I., and Neimark, A. V. (2006). Density functional theory model of adsorption on amorphous and microporous silica materials. Langmuir 22, 11171-11179. doi: 10.1021/la0616146

Reddy, M. A., Breitung, B., and Fichtner, M. (2013). Improving the energy density and power density of $\mathrm{CF}_{\mathrm{x}}$ by mechanical milling: a primary lithium battery electrode. ACS Appl. Mater. Inter. 5, 11207-11211. doi: 10.1021/am403438m

Sato, Y., Itoh, K., Hagiwara, R., Fukunaga, T., and Ito, Y. (2004). On the socalled "semi-ionic" C-F bond character in fluorine-GIC. Carbon 42, 3243-3249 doi: 10.1016/j.carbon.2004.08.012

Shao, Y., Yue, H., Qiao, R., Hu, J., Zhong, G., and Wu, S., et. al. (2016). Synthesis and reaction mechanism of novel fluorinated carbon fiber as a high-voltage cathode material for rechargeable Na batteries. Chem. Mater. 28, 1026-1033. doi: 10.1021/acs.chemmater.5b03762

Shulga, Y. M., Tien, T.-C., Huang, C.-C., Lo, S.-C., Muradyan, V. E., Polyakova, N. V., et al. (2007). XPS study of fluorinated carbon multi-walled nanotubes. J. Electron. Spectrosc. Relat. Phenom. 160, 22-28. doi: 10.1016/j.elspec.2007.06.002

Sideris, P. J., Yew, R., Nieves, I., Chen, K., Jain, G., Schmidt, C. L., et al. (2014). Charge transfer in $\mathrm{Li} / \mathrm{CF}_{\mathrm{x}}$-silver vanadium oxide hybrid cathode batteries revealed by solid state ${ }^{7} \mathrm{Li}$ and ${ }^{19} \mathrm{~F}$ nuclear magnetic resonance spectroscopy. J. Power Sources 254, 293-297. doi: 10.1016/j.jpowsour.2013.12.108

Sun, C., Feng, Y., Li, Y., Qin, C., Zhang, Q., and Feng, W. (2014). Solvothermally exfoliated fluorographene for high-performance lithium primary batteries. Nanoscale 6, 2634-2641. doi: 10.1039/C3NR04609E

Tressaud, A., Moguet, F., Flandrois, S., Chambon, M., Guimon, C., Nanse, G., et al. (1996). On the nature of C-F bonds in various fluorinated carbon materials: XPS and TEM investigations. J. Phys. Chem. Solids 57, 745-751. doi: 10.1016/0022-3697(96)00343-5

Wang, B., Wang, J., and Zhu, J. (2014). Fluorination of graphene: a spectroscopic and microscopic study. ACS Nano 8, 1862-1870. doi: 10.1021/nn406333f 
Wang, S., Liu, Q., Yu, J., and Zeng, J. (2012). Anisotropic expansion and high rate discharge performance of $\mathrm{V}$-doped $\mathrm{MnO}_{2}$ for $\mathrm{Li} / \mathrm{MnO}_{2}$ primary battery. Int. J. Electrochem. Sci. 7, 1242-1250.

Wang, X., Wang, W., Liu, Y., Ren, M., Xiao, H., and Liu, X. (2016). Controllable defluorination of fluorinated graphene and weakening of C-F bonding under the action of nucleophilic dipolar solvent. Phys. Chem. Chem. Phys. 18, 3285-3293. doi: 10.1039/C5CP06914A

Yazami, R., Hamwi, A., Guérin, K., Ozawa, Y., Dubois, M., Giraudet, J., et al. (2007). Fluorinated carbon nanofibres for high energy and high power densities primary lithium batteries. Electrochem. Commun. 9, 1850-1855. doi: 10.1016/j.elecom.2007.04.013

Yue, H., Zhang, W., Liu, H., Liu, Z., Zhong, G., and Yang, Y. (2013). Synthesis and characterization of fluorinated carbon nanotubes for lithium primary batteries with high power density. Nanotechnology 24:424003. doi: 10.1088/0957-4484/24/42/424003

Zhang, Q., D'Astorg, S., Xiao, P., Zhang, X., and Lu, L. (2010). Carbon-coated fluorinated graphite for high energy and high power densities primary lithium batteries. J. Power Sources 195, 2914-2917. doi: 10.1016/j.jpowsour.2009.10.096

Zhang, Q., Takeuchi, K. J., Takeuchi, E. S., and Marschilok, A. C. (2015). Progress towards high-power Li/CFx batteries: electrode architectures using carbon nanotubes with CFx. Phys. Chem. Chem. Phys. 17, 22504-22518. doi: 10.1039/C5CP03217B

Zhang, S. S., Foster, D., Wolfenstine, J., and Read, J. (2009). Electrochemical characteristic and discharge mechanism of a primary Li/CFx cell. J. Power Sources 187, 233-237. doi: 10.1016/j.jpowsour.2008.10.076

Zhang, W., Dubois, M., Guérin, K., Bonnet, P., Kharbache, H., Masin, F., et al. (2010). Effect of curvature on C-F bonding in fluorinated carbons: from fullerene and derivatives to graphite. Phys. Chem. Chem. Phys. 12, 1388-1398. doi: 10.1039/B914853A

Zhang, W., Dubois, M., Guérin, K., Bonnet, P., Petit, E., Delpuech, N., et al. (2009). Effect of graphitization on fluorination of carbon nanocones and nanodiscs. Carbon 47, 2763-2775. doi: 10.1016/j.carbon.2009.05.035

Zhao, F.-G., Zhao, G., Liu, X.-H., Ge, C.-W., Wang, J.-T., Li, B.-L., et al. (2014). Fluorinated graphene: facile solution preparation and tailorable properties by fluorine-content tuning. J. Mater. Chem. A 2, 8782-8789. doi: 10.1039/C4TA00847B

Zhu, Y., Zhang, L., Zhao, H., and Fu, Y. (2017). Significantly improved electrochemical performance of $\mathrm{CF}_{\mathrm{x}}$ promoted by $\mathrm{SiO}_{2}$ modification for primary lithium batteries. J. Mater. Chem. A 5, 796-803. doi: 10.1039/C6TA07919A

Conflict of Interest Statement: The authors declare that the research was conducted in the absence of any commercial or financial relationships that could be construed as a potential conflict of interest.

The reviewer XJ, and handling Editor declared their shared affiliation.

Copyright (c) 2018 Zhong, Chen, Huang, Yue and Lu. This is an open-access article distributed under the terms of the Creative Commons Attribution License (CC $B Y)$. The use, distribution or reproduction in other forums is permitted, provided the original author(s) and the copyright owner are credited and that the original publication in this journal is cited, in accordance with accepted academic practice. No use, distribution or reproduction is permitted which does not comply with these terms. 